\title{
PENILAIAN TINGKAT KESEHATAN BANK DENGAN RASIO PROFITABILITAS PADA PT. BANK AGRIS TBK TAHUN 2013-2017
}

\author{
Camelia Verahastuti ${ }^{1}$ \\ Ivana Nina Esterlin Barus ${ }^{2}$ \\ University of 17 Agustus 1945 Samarinda \\ J1. Ir. H. Juanda No. 80, 75124, Indonesia \\ 1cameliaverahastuti1981@gmail.com \\ ${ }^{2}$ wiliva.couple@gmail.com
}

\begin{abstract}
The purpose of this study was to determine the assessment of the Bank's soundness with Profitability Ratio at PT. Bank Agris in 2013-2017 in terms of ROA.

The analytical tool used is Return on Assets (ROA). The data needed is 5 years from 2013 to 2017 obtained from the Indonesia Stock Exchange. The results of this study: ROA in 2013 had a fairly healthy predicate then in 2014, 2015 and 2016 it fell to be unhealthy and 2017 decreased again to become unhealthy.

The results of the hypothesis of this study Bank health rating with the RGEC method at PT. Bank Agris Tbk in 2013-2017 based on: 2013 ROA has a fairly healthy predicate then in 2014,2015 and 2016 it declined to be less healthy and 2017 declined again to become unhealthy, the hypothesis was rejected
\end{abstract}

Keywords: Return On Assets (ROA), probability ratio, financial management

\section{PENDAHULUAN}

Perbankan adalah suatu industri yang bergerak di bidang keuanguatu negara. Dalam rangka mencapai sisteman yang berperan sebagai kemajuan perekonomian s perbankan yang kuat, sehat serta efisien maka Bank Indonesia melakukan proses konsolidasi terhadap Perbankan Indonesia.

Faktor yang dapat mempengaruhi kinerja keuangan bank yaitu melemahnya nilai tukar rupiah, lemahnya kondisi internal bank seperti kinerja manajemen yang kurang memadai dan pemberian kredit kepada kelompok usaha pribadi yang dapat mengakibatkan kredit macet, selain itu tingkat kompleksitas usaha yang tinggi dapat meningkatkan risikorisiko yang dihadapi oleh perbankan dan dapat menyebabkan kinerja bank menurun. Sehingga diperlukannya penilaian tingkat kesehatan bank untuk mengetahui sehat atau tidak sehat kondisi suatu bank.

$$
\text { Menurut Kasmir }
$$
definisi rasio profitabilitas merupakan rasio untuk menilai kemampuan perusahaan dalam mencari keuntungan. 
Rasio ini juga memberikan ukuran tingkat efektivitas manajemen suatu perusahaan. Hal ini ditunjukkan oleh laba yang dihasilkan dari penjualan dan pendapatan investasi. Initinya bahwa penggunaan rasio ini menunjukkan efisiensi perusahaan.

Bank Agris didirikan di Jakarta dengan nama PT Finconesia ("Finconesia") sesuai dengan peraturan Keputusan Menteri Keuangan Republik Indonesia No. Kep. 792/MK/IV/12/1970 tanggal 7 Desember 1970 dan berdasarkan Akta Perseroan Terbatas No. 85 tanggal 13 Nopember 1973 juncto Akta Perubahan No. 315 tanggal 29 Maret 1974. Finconesia merupakan lembaga keuangan yang pada saat itu sahamnya dipegang oleh PT Bank Negara Indonesia 1946, The Nomura Securities Co. Ltd, Barclays Bank International Limited, Manufacturers Hanover International Finance Corporation, The Mitsui Bank Ltd, Banque Francaise Du Commerce Exterieur dan Commerzbank Aktiengesellschaft.

Tahun 1993, Finconesia berubah dari lembaga keuangan menjadi Bank Umum berdasarkan Surat Keputusan Menteri Keuangan Republik Indonesia No. 442/KMK.017/1993 tanggal 9 Maret 1993 sehingga nama Finconesia berubah menjadi PT Bank Finconesia ("Bank Finconesia"). Tahun 2008, nama Bank Finconesia resmi berubah nama menjadi Bank Agris berdasarkan Akta Perseroan Terbatas No.146 tanggal 18 Juli 2008 yang dibuat di hadapan Sutjipto, SH, M.Kn, Notaris di Jakarta dan telah diumumkan dalam SK Menkumham No. AHU-45703.AH.01.02 tahun 2008, tanggal 29 Juli 2008 (Akta No. 146/2008) yang juga merupakan penyesuaian atas Undang-undang No. 40 Tahun 2007 ("UUPT").

Tahun 2014, Bank Agris telah melakukan penawaran umum perdana saham (Initial Public Offering /IPO) dan telah mencatatkan sahamnya di Bursa Efek Indonesia. Dengan demikian Bank Agris telah menjadi perusahaan terbuka dengan nama PT Bank Agris Tbk, sesuai Akta Perseroan Terbatas Nomor 43 tanggal 28 Agustus 2014 yang dibuat di hadapan Fathiah Helmi, SH. Notaris di Jakarta dan telah diumumkan dalam SK Menkumham No. AHU07146.40.20.2014.

Tahun 2015, Bank Agris melakukan Penawaran Umum Terbatas I ("PUT I"), sesuai dengan Akta Perseroan Terbatas No.101 tanggal 20 Januari 2016 yang dibuat dihadapan Dr. Irawan Soerodjo SH, MSi, Notaris di Jakarta dan 
telah diterima dan dicatat dalam sistem Administrasi Badan Hukum, sebagaimana ternyata dalam suratnya tanggal 27 Januari 2016 No.AHUАН.01.03.0006753.

Bank Agris telah memiliki 23 jaringan kantor yang terdiri dari satu kantor cabang utama, sembilan kantor cabang, tiga kantor cabang pembantu, empat kantor kas, dan enam kantor fungsional. Tersebar di Tangerang Selatan, Jakarta, Bandung, Solo, Semarang, Surabaya, Pontianak, Bandar Lampung, Pekanbaru, Palembang, Medan. Sebagai bank umum swasta nasional, Bank menawarkan berbagai produk kepada nasabah dalam bentuk simpanan dan pinjaman, yaitu: Simpanan berupa deposito, giro, tabungan agris, tabungan agris plus. Sedangkan pinjaman berupa kredit modal kerja, kredit investasi, kredit konsumsi/konsumtif, kerjasama pembiyaan, kredit khusus untuk peternak ayam dan tambak udang serta Produk Treasury tugas pokok Treasury ditujukan kepada pengelolaan likuiditas bank dalam memenuhi kewajiban-kewajibannya. Pengelolaan likuiditas mengacu kepada kewajiban pemenuhan ketentuan rasio GWM (Giro Wajib Minimum) dalam mata uang Rupiah dan Valas serta beberapa rasio lainnya yang telah ditetapkan oleh Bank Indonesia. Treasury wajib menjaga rasiorasio tersebut selalu dalam target yang telah ditetapkan oleh Bank Indonesia dan otoritas jasa keuangan. Aktifitas transaksi yang dilakukan oleh Treasury di dalam Dealing Room meliputi aktifitas transaksi Money Market antar bank, transaksi valuta asing dan surat berharga. Transaksi Money Market Interbank dilakukan untuk kebutuhan pengaturan likuiditas dan sebagai transaksi untuk tujuan Trading maupun Arbitrage. Produk Money Market interbank yang telah dipergunakan berupa Callmoney dengan variasi jatuh tempo, NCD (Negotiable Certificate Deposit) dan Instrument Bank Indonesia

Perolehan laba bersih yang dilihat dari laporan keuangan menunjukan laba bersih dari tahun 2013-2017 pada PT.Bank Agris Tbk mengalami penurunan , maka penting untuk melakukan tingkat penilaian kesehatan bank agar dapat mengetahui jika perolehan laba bersih suatu bank mengalami penurunan apakah bank tersebut masih bisa di nilai sehat atau tidak sehat agar mempertahankan kepercayaan masyarakat dan tetap memperkuat posisi Bank Agris sebagai salah satu institusi penyedia layanan 
transaksi dan pembayaran yang ada di Indonesia.

\section{KERANGKA TEORITIS}

\section{Manajemen Keuangan}

Menurut James C. van Horne dalam Kasmir (2010:5) manajemen keuangan adalah: "Segala aktivitas yang berhubungan dengan perolehan, pendanaan dan pengelolaan aktiva dengan beberapa tujuan menyeluruh".

Menurut James C. Van Horne dan John M. Wachowicz, Jr. (2009:2) manajemen keuangan adalah : "Financial management is concerned with the acquisition, financing, and management of assets with some overall goal in mind".

\section{Laporan Keuangan}

Pengertian laporan keuangan menurut Hampton dalam Rao (2011:22) adalah : “ $A$ financial statement is an organized collection of data according to logical and consistent accounting procedures".

Menurut Kasmir (2010:66) laporan keuangan adalah :

"Salah satu cara untuk mengetahui kinerja perusahaan dalam satu periode tertentu. Apa yang dilaporkan kemudian dianalisis, sehingga dapat diketahui kondisi dan posisi keuangan terkini. Dengan melakukan analisis akan diketahui letak kelemahan dan kekuatan perusahaan."

\section{Laporan Keuangan Bank}

Laporan keuangan bank menurut Nurul Ichsan Hasan (2014:41) adalah : "Badan usaha yang kekayaannya terutama dalam bentuk aset keuangan (financial Assets) atau tagihan (claims) dibandingkan aset non finansial atau asel rill”.

Menurut Ismail (2010:15) laporan keuangan bank adalah:

"Bentuk pertanggung jawaban manajemen terhadap pihak-pihak yang berkepentingan dengan kinerja bank yang dicapai selama periode tertentu".

\section{Pengertian Bank}

Pengertian bank menurut Nurul Ichsan Hasan (2014:3) adalah: "Lembaga keuangan yang kegiatan utamanya adalah menghimpun dana dari masyarakat dan menyalurkan kembali dana tersebut ke masyarakat serta memberikan jasa-jasa bank lainnya".

\section{Menurut Undang-Undang RI} nomor 10 Tahun 1998 tanggal 10 November 1998 tentang perbankan pengertian bank adalah :

"Bank adalah badan usaha yang mengimpun dana dari masyarakat dalam bentuk simpanan dan menyalurkan kepada masyarakat dalam “ 
Fungsi Bank

Fungsi bank menurut Totok Budisantoso dan Nuritmo (2014:9) adalah: "Fungsi utama bank adalah menghimpun dana dari masyarakat dan menyalurkan kembali kepada masyarakat untuk berbagai tujuan atau sebagai Financial intermediary”.

\section{Tingkat Kesehatan Bank}

Menurut Nurul Ichsan Hasan (2014:177) Tingkat kesehatan bank adalah: "Kemampuan suatu bank untuk melakukan kegiatan operasional perbankan secara normal dan mampu memenuhi semua kewajiban dengan baik dan sesuai dengan peraturan perbankan yang berlaku".

\section{METODE PENELITIAN}

Teknik pengumpulan data yang digunakan dalam penelitian ini adalah Penelitian Kepustakaan (Library reseach). Penelitian dilakukan dengan menggunakan metode dokumentasi yaitu mengumpulkan data sekunder dan laporan yang diperlukan. Dokumen yang diperlukan dalampenelitian ini adalah laporan keuangan bank pada PT.Bank Agris Tbk tahun 2013-2017 yang di akses melalui www.idx.co.id dan di situs web Bank Agris.

Alat analisis yang digunakan adalah analisis laporan keuangan dengan menggunakan Rasio Profitabilitas menggunakan ROA (Return On Asset):

Return On Assets (ROA)

$$
\text { ROA }=\frac{\text { Laba Sebelum Pajak }}{\text { Rata }- \text { Rata Total Aset }} \times 100 \%
$$

Tabel 1.4. : Matriks Kriteria Penetapan Peringkat Komposit ROA

\begin{tabular}{ccc}
\hline Peringkat & Predikat & Rasio ROA \\
\hline 1 & Sangat Sehat & ROA $>1,5 \%$ \\
2 & Sehat & $1,25 \%<\mathrm{ROA} \leq 1,5 \%$ \\
3 & Cukup Sehat & $0,5 \%<\mathrm{ROA} \leq 1,25 \%$ \\
4 & Kurang Sehat & $0 \%<\mathrm{ROA} \leq 0,5 \%$ \\
5 & Tidak Sehat & $\mathrm{ROA} \leq 0 \%$ (Negatif) \\
\hline
\end{tabular}

(sumber : Lampiran SE BI 13/24/DPNP/2011)

\section{ANALISIS DAN PEMBAHASAN}

\section{Analisis}

Penilaian tingkat kesehatan bank pada tahun 2013,2014,2015,2016, dan 2017 dengan Rasio Profitabilitas menggunakan
ROA ( Return On Asset) maka hasil analisis sebagai berikut :

\section{Return On Assets (ROA)}

$$
\text { ROA }=\frac{\text { Laba Sebelum Pajak }}{\text { Rata }- \text { Rata Total Aset }} \text { X100\% }
$$


Tabel 2.4 : Rekapitulasi Perhitungan ROA (Return On Assets) pada PT.Bank Agris Tbk Tahun 2013-2017

\begin{tabular}{ccccc}
\hline No & Tahun & Laba Sebelum Pajak & Rata-rata Total Aktiva & ROA \\
\hline 1 & 2013 & Rp14.396.000.000 & Rp1.861.710.000.000 & $0,77 \%$ \\
2 & 2014 & Rp8.256.000.000 & Rp3.310.159.000.000 & $0,25 \%$ \\
3 & 2015 & Rp6.450.000.000 & Rp4.164.202.000.000 & $0,15 \%$ \\
4 & 2016 & Rp6.263.000.000 & Rp4.138.659.000.000 & $0,15 \%$ \\
5 & 2017 & -Rp7.319.000.000 & Rp3.976.233.000.000 & $-0,18 \%$ \\
\hline
\end{tabular}

(Sumber : Data diolah, 2019)

Pembahasan

Return On Assets (ROA)
2013-2017 Berdasarkan ROA (Return On Asset)

Tabel 3.4 : Rekapitulasi Tingkat

Kesehatan PT.Bank Agris Tbk Tahun

\begin{tabular}{cccc}
\hline No & Tahun & Rasio ROA & Predikat \\
\hline 1 & 2013 & $0,77 \%$ & Cukup Sehat \\
2 & 2014 & $0,25 \%$ & Kurang Sehat \\
3 & 2015 & $0,15 \%$ & Kurang Sehat \\
4 & 2016 & $0,15 \%$ & Kurang Sehat \\
5 & 2017 & $-0,18 \%$ & Tidak Sehat \\
\hline
\end{tabular}

(Sumber : Data Diolah, 2019)

Hasil penelitian ROA pada laba di Bank tersebut semakin menurun.

PT.Bank Agris Tbk dari 2013-2017 mengalami penurunan yang artinya kemampuan perusahaan menghasilkan laba di Bank tersebut semakin menurun.

\section{KESIMPULAN}

Berdasarkan hasil peneilitian dan pembahasan yang telah dilakukan sebelumnya maka dapat ditarik kesimpulan sebagai berikut : Hasil penelitian ROA (Return On Assets) pada PT.Bank Agris Tbk dari 2013-2017 mengalami penurunan yang artinya kemampuan perusahaan menghasilkan
Tahun 2013 memiliki predikat cukup sehat kemudian pada tahun 2014,2015 dan 2016 menurun menjadi kurang sehat kemudian 2017 mengalami penurunan lagi menjadi tidak sehat.

\section{SARAN}

Saran bagi pihak manajemen perusahaan PT.Bank Agris Tbk agar dapat memperbaiki kekurangan yang ada agar Bank ini dapat tetap bertahan sampai selanjutnya, dan mempertahankan kelebihan yang sudah ada. Saran bagi peneliti selanjutnya 
adalah agar meneliti Bank lain dan membandingkan tingkat kesehatanya

\section{DAFTAR PUSTAKA}

Anonim, Peraturan Bank Indonesia No.13/PBI/2011 Tanggal 25 Oktober 2011.

Surat Edaran Bank Indonesia No.13/24/DPNP/2011 Tanggal 25 Oktober 2011.

Barus, Ivana Nina Esterlin. 2016. Pengaruh GCG terhadap Kinerja Keuangan dengan CSR sebagai Pemoderasi di Perusahaan Pertambangan. Jurnal Manajemen dan Keuangan, Vol 5, No.1.

Budisantoso, Totok dan Nuritmo. 2014. Bank dan Lembaga Keuangan Lain. Jakarta: Salemba Empat.

Fahmi, Irham. 2015. Pengantar Manajemen Keuangan Teori dan Soal Jawab. Cetakan Keempat. Bandung: Alfabeta.

Harjito D. Agus dan Martono. 2012. Manajemen Keuangan. Edisi Kedua. Cetakan Kedua. Yogyakarta: Ekonisia.

Harmono. 2016. Manajemen Keuangan Berbasis Balanced Scorecard Pendekatan Teori, Kasus, dan Riset Bisnis. Cetakan Kelima. Jakarta: PT Bumi Aksara.

Hasan, Nurul Ichsan. 2014. Pengantar Perbankan. Edisi Pertama. Jakarta: Anggota IKAPI.

Ikatan Bankir Indonesia. 2016. Manajemen Kesehatan Bank Berbasis Risiko. Jakarta: PT Gramedia Pusaka Utama.

Ismail. 2010. Manajemen Perbankan Dari Teori Menuju Aplikasi. dengan Bank yang sejenisnya dengan menggunakan variabel yang lain.

Jakarta: Kencana.

Kasmir. 2010. Pengantar Manajemen Keuangan. Edisi Pertama. Cetakan Pertama. Jakarta: Prenada Media.

$\begin{array}{lrrr}\text { 2012. } & \text { Analisis } & \text { Laporan } \\ \text { Keuangan. } & \text { Edisi } & \text { Keempat. } \\ \text { Jakarta: PT } & \text { Raja } & \text { Grafindo } \\ \text { Persada. }\end{array}$

Pramana, Komang Mahendra. 2016. Analisis Tingkat Kesehatan Bank (Pendekatan RGEC) pada PT.Bank Danamon Indonesia Tbk. E-jurnal Manajemen Unud, Vol. 5, No. 6.

Rao, Peddina Mohana. 2011. Financial Statement Analysis and Reporting. New Delhi: PHI Learning.

Rudianto. 2012. Pengantar Akuntansi Konsep dan Teknik Penyususnan Laporan Keuangan. Jakarta: Erlangga.

Sutrisno. 2009. Manajemen Keuangan Teori, Konsep dan Aplikasi. Cetakan Kelima. Yogyakarta: Ekonisia.

2013. Manajemen Keuangan Teori, Konsep dan Aplikasi. Cetakan Kesembilan. Yogyakarta: Ekonisia.

Undang-Undang RI nomor 10 Tahun 1998 tanggal 10 November 1998.

Van Horne, James and Jhon Wachowiz. 2009. Fundamentals of Financial Management $13^{\text {th }}$ Edition. England: Prentice Hal 